\title{
A fluorimetric enzyme assay for the diagnosis of Sanfilippo disease type A (MPS IIIA)
}

\author{
E. A. Karpova ${ }^{1}$, Ya. V. Voznyi ${ }^{2}$, J. L. M. Keulemans ${ }^{1}$, A. T. Hoogeveen ${ }^{1}$, \\ B. WinCHESTER ${ }^{3}$, I. V. TSVETKOVA ${ }^{4}$ and O. P. VAN DIGGELEN ${ }^{1 *}$ \\ 'Department of Clinical Genetics, Erasmus University, Rotterdam, The Netheriands; \\ ${ }^{2}$ Institute of Organic Chemistry, Moscow, Russia, ${ }^{3}$ Division of Biochemistry and Genetics, \\ Institute of Child Health, London, UK; ${ }^{4}$ Institute of Biomedical Chemistry, Moscow, Russia \\ *Correspondence: Department of Clinical Genetics, Erasmus University, PO Box 1738 , \\ 3000 DR Rotterdam, The Netherlands
}

MS received 12.10.95 Accepted 5.12.95

\begin{abstract}
Summary: 4-Methylumbelliferyl- $\alpha$-D-N-sulphoglucosaminide (MU- $\alpha$-GlcNS) was synthesized and shown to be a substrate for the lysosomal heparin sulphamidase. Sanfilippo A patients' fibroblasts $(n=42)$ and lymphocytes $(n=1)$ showed $0-3 \%$ of mean normal heparin sulphamidase activity; in total leukocytes from patients $(n=8)$ sulphamidase activity was clearly deficient. In fibroblasts from obligate heterozygotes for Sanfilippo A, the sulphamidase activity was reduced in 9 out of 10 cases. Heparin sulphamidase desulphates MU- $\alpha \mathrm{GlcNS}$ to $\mathrm{MU}-\alpha \mathrm{GlcNH}_{2}$ and further hydrolysis during a second incubation is required to liberate 4-methylumbelliferone, which can be measured. Yeast $\alpha$-glucosidase, which has low but sufficient $\alpha$-glucosaminidase activity, was used to hydrolyse the reaction intermediate $\mathrm{MU}-\alpha \mathrm{GlcNH}_{2}$ to release 4-methylumbelliferone and free glucosamine.
\end{abstract}

Sanfilippo disease (mucopolysaccharidosis type III, MPS III) comprises four different autosomal recessive subtypes (for review see Neufeld and Muenzer 1995) and is clinically characterized by severe central nervous system degeneration but only mild somatic abnormalities. Owing to different defects in the degradation of heparan sulphate, patients store excessive amounts of this mucopolysaccharide in various tissues.

MPS III type A is caused by a deficiency of heparin sulphamidase (EC 3.10.1.1; Kresse et al 1973). Although the mucopolysaccharidoses are rare disorders, MPS IIIA is relatively common. Heparin sulphamidase is routinely assayed using $\left[\mathrm{N}^{-35}\right.$-sulphonate]heparin (Kresse et al 1973). This assay has many pitfalls related to the instability and short halflife of the substrate and the poor relationship between amount of enzyme and activity. The use of $\left[{ }^{3} \mathrm{H}\right]$ heparin-derived oligosaccharides has overcome most of these difficulties (Hopwood and Elliot 1981a,b, 1982).

In this paper we describe a novel, simple fluorimetric assay for heparin sulphamidase, using 4-methylumbelliferyl- $\alpha$-D- $N$-sulphoglucosaminide, and show its usefulness in the diagnosis of MPS IIIA. 


\section{MATERIALS AND METHODS}

4-Methylumbelliferyl- $\alpha$-D- $N$-sulphoglucosaminide (MU- $\alpha \mathrm{GlcNS}$; 2-sulphamino-2-deoxyD-glucopyranosyl $\alpha 1$-[4-methylumbelliferone]) has been synthesized by selective $\mathrm{N}$ sulphation of the free amino group in 4-methylumbelliferyl- $\alpha$-D-glucosaminide by an excess of triethylamine-sulphur trioxide complex in dimethylformamide-methanol solution. After purification of the resulting mixture, by passing through a cation exchange resin and substitution of triethylamino group to sodium, the product was lyophilized. The synthesis of starting material with free amino group was described earlier (Voznyi et al 1991).

Total leukocytes were isolated from heparinized blood as described previously (van Diggelen et al 1990), and lymphocytes were prepared using LymphoSep (ICN Flow). The white blood cells were frozen before use. Skin fibroblasts were cultured according to routine procedures in Ham's F10 medium supplemented with 15\% fetal bovine serum and antibiotics. The cells were harvested with trypsin 7 days after the last subculture and stored at $-80^{\circ} \mathrm{C}$ until use. Fibroblasts from patients with Sanfilippo types A, B, C and D or multiple sulphatase deficiency were obtained from the European Human Cell Bank, Rotterdam, The Netherlands (Dr W. J. Kleijer).

Homogenates were prepared by sonication of cell material in water. The standard heparin sulphamidase reaction mixtures for fibroblasts and lymphocytes consisted of $10 \mu \mathrm{l}$ homogenate (10 or $15 \mu \mathrm{g}$ protein, respectively) and $20 \mu \mathrm{l} \mathrm{MU}-\alpha \mathrm{GlcNS}(5$ or $10 \mathrm{mmol} / \mathrm{L}$, respectively) in Michaelis' barbital sodium acetate buffer, $\mathrm{pH} 6.5(29 \mathrm{mmol} / \mathrm{L}$ sodium barbital, $29 \mathrm{mmol} / \mathrm{L}$ sodium acetate, $0.68 \%(\mathrm{w} / \mathrm{v}) \mathrm{NaCl}, 0.02 \%(\mathrm{w} / \mathrm{v})$ sodium azide; adjusted to $\mathrm{pH} 6.5$ with $\mathrm{HCl}$ ) and the reaction mixtures were incubated for $17 \mathrm{~h}$ at $37^{\circ} \mathrm{C}$ or $47^{\circ} \mathrm{C}$, respectively. MU- $\alpha$ GlcNS is available from Moscerdam Substrates (for inquiries: O.P. van Diggelen, Rotterdam). The standard assay for leukocytes was different: $10 \mu \mathrm{l}$ homogenate ( $60 \mu \mathrm{g}$ protein) plus $20 \mu \mathrm{l} 10 \mathrm{mmol} / \mathrm{L}$ MU- $\alpha \mathrm{GlcNS}$ in barbital/sodium acetate buffer, $\mathrm{pH}$ 6.5 (see above), containing $0.225 \mathrm{mg} / \mathrm{ml}$ Pefabloc (a protease inhibitor from Boehringer; not stable in solution) was incubated for $17 \mathrm{~h}$ at $47^{\circ} \mathrm{C}$. For all assays, after the first incubation at either $37^{\circ} \mathrm{C}$ or $47^{\circ} \mathrm{C}, 6 \mu \mathrm{l}$ twice-concentrated Mcllvain's phosphate/citrate buffer, $\mathrm{pH}$ 6.7 , containing $0.02 \%$ sodium azide and $10 \mu \mathrm{l}(0.1 \mathrm{U})$ yeast $\alpha$-glucosidase (Sigma) in water were added and a second incubation of $24 \mathrm{~h}$ at $37^{\circ} \mathrm{C}$ was carried out. Long incubations at $37^{\circ} \mathrm{C}(17-24 \mathrm{~h})$ were carried out in 96-well titreplates which were sealed airtight with broad sticky tape, limiting evaporation to $<15 \%$. Incubations at $47^{\circ} \mathrm{C}$ were carried out, in Eppendorf tubes, under oil, to prevent evaporation; after the first incubation, the mixtures were transferred quantitatively to the wells of a titreplate and the second incubation was carried out as described above.

Next, $200 \mu \mathrm{l} 0.5 \mathrm{~mol} / \mathrm{L} \mathrm{Na}_{2} \mathrm{CO}_{3} / \mathrm{NaHCO}_{3}, \mathrm{pH} 10.7$, was added and the fluorescence of the released 4-methylumbelliferone (MU) was measured on a Fluoroskan (Titertek) fluorimeter.

Protein was determined as described previously (van Diggelen et al 1990).

\section{RESULTS}

The potential of 4-methylumbelliferyl- $\alpha$-D- $N$-sulphoglucosaminide (MU- $\alpha \mathrm{GlcNS}$ ) as substrate for the heparin sulphamidase was investigated. The liberation of MU from MU$\alpha$ GlcNS cannot be accomplished by the sole action of heparin sulphamidase, since this enzyme only cleaves the $N$-sulphate, yielding $\mathrm{MU}-\alpha \mathrm{GlcNH}_{2}$. In previous studies we had 


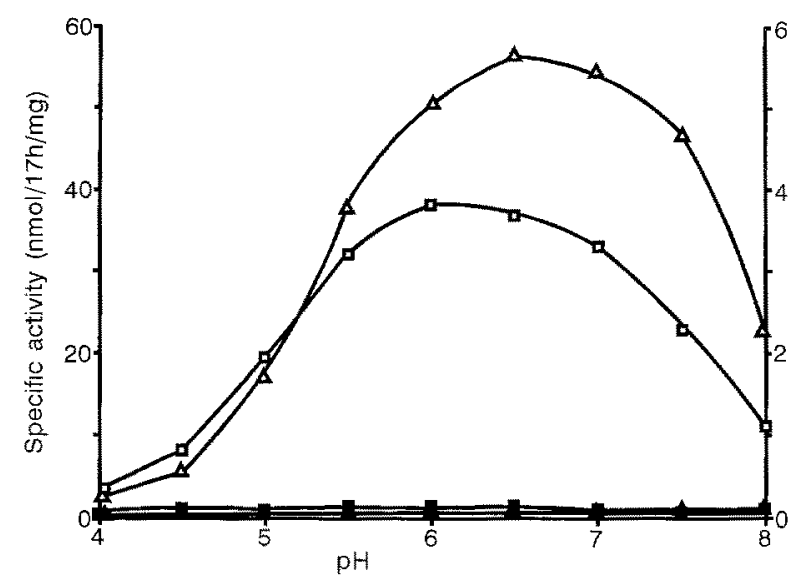

Figure $1 \mathrm{pH}$-dependence of heparin sulphamidase activity. Fibroblasts from a control $(\triangle)$ and a Sanfilippo A patient ( $\mathbf{\Delta}$ ); leukocytes from a control ( $\square$ ) and a Sanfilippo patient ( $\mathbf{\square})$. Triangles, left scale; squares, right scale. Reaction conditions as in standard assay, except for $\mathrm{pH}$

found that $\alpha$-glucosidase from various sources has low, but significant, $\alpha$-glucosaminidase activity towards $\mathrm{MU}-\alpha$-GlcNH , releasing free glucosamine (Wang He et al, unpublished observation). We applied this observation to our sulphamidase assay by subjecting the reaction mixtures to a second incubation $\left(24 \mathrm{~h}\right.$ at $\left.37^{\circ} \mathrm{C}\right)$ in the presence of $0.1 \mathrm{U}$ yeast $\alpha$-glucosidase, which caused complete hydrolysis of the reaction intermediate MU- $\alpha$ $\mathrm{GlcNH}_{2}$ between 10 and 1000 pmol.

In the experiments described below, heparin sulphamidase was assayed under standard conditions in barbital/sodium acetate buffer as described in the Materials and Methods section (except for the condition which was being investigated). The $\mathrm{pH}$ optimum of heparin sulphamidase from fibroblasts and leukocytes was $\mathrm{pH} 6.5$, whereas fibroblasts and leukocytes from a Sanfilippo A patient had practically no activity in the $\mathrm{pH}$ range tested (Figure 1). The apparent $K_{\mathrm{m}}$ was estimated to be $4 \mathrm{mmol} / \mathrm{L}$ for fibroblasts and $8 \mathrm{mmol} / \mathrm{L}$ for leukocytes (Figure 2). The sulphamidase activity increased nearly linearly with protein up to $20 \mu \mathrm{g}$ for fibroblasts and up to $60 \mu \mathrm{g}$ for leukocytes (Figure 3). A nearly linear rate of reaction was observed over a period of up to $17 \mathrm{~h}$ incubation (Figure 4). Michaelis' barbital/sodium acetate buffer was the only buffer found useful at $\mathrm{pH} 6.5$, since the more commonly used buffers were inhibitory (Table 2). Phosphates and sulphates are also powerful inhibitors in our standard sulphamidase assay (Table 2).

Under the standard conditions of fibroblast assay, heparin sulphamidase activity was readily detectable in lymphocytes but barely detectable in total leukocytes. Compared to fibroblasts and lymphocytes, the activity in leukocytes was unexpectedly low, and we considered that sulphamidase was being degraded by granulocyte proteases during the long incubation at a neutral $\mathrm{pH}(6.5)$. Several protease inhibitors were tested and a mixture prepared by Boehringer (Pefabloc) greatly increased sulphamidase activity. Heparin sulphamidase is a very heat-stable enzyme, and this has been exploited to increase sulphamidase activity by incubation at elevated temperatures (Whiteman and Young 1977; Hopwood and Elliott 1981a,b, 1982). In our assay, raising the incubation temperature from 

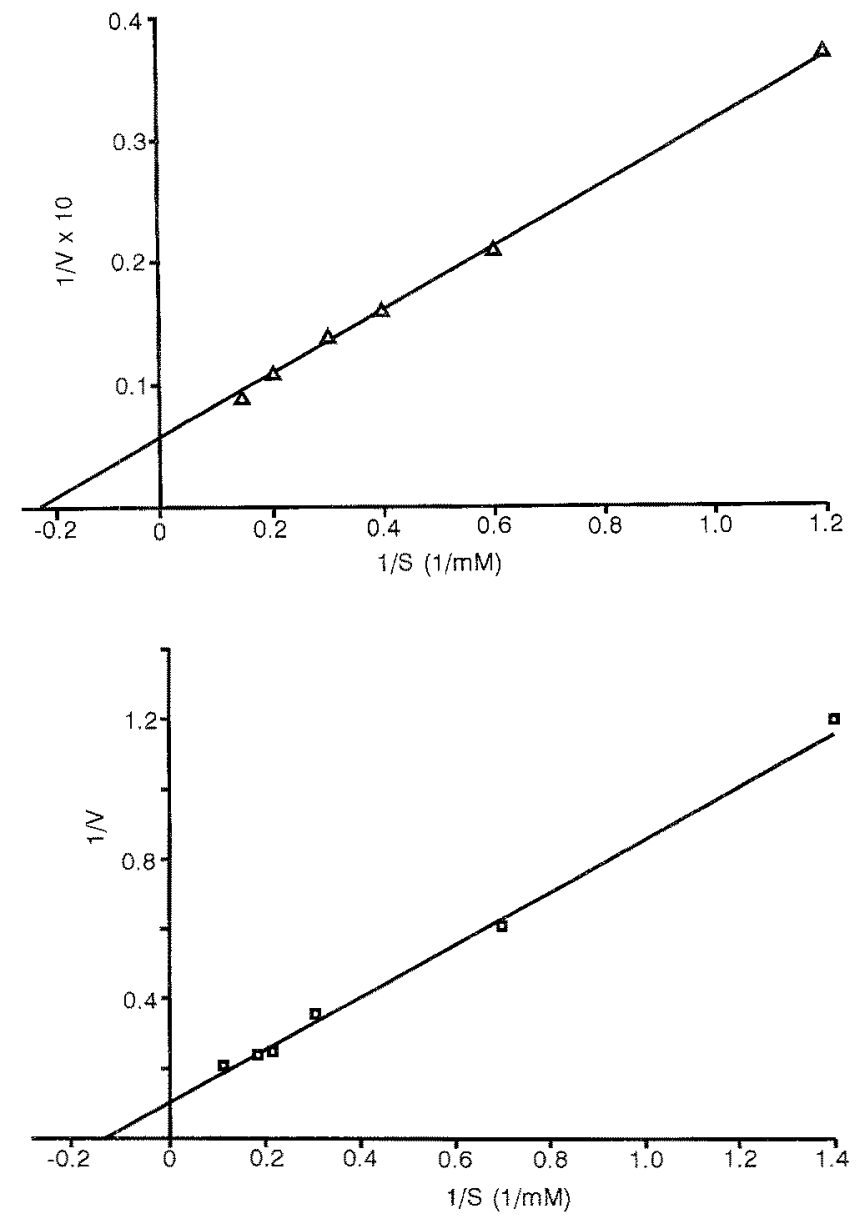

Figure 2 Lineweaver-Burk plot for heparin sulphamidase activity with MU- $\alpha$ GlcNS. Normal fibroblasts (upper panel) and leukocytes (lower panel). $V$ is in units of nmol/17h per $\mathrm{mg}$ protein. Reaction conditions as in standard assay, except for MU- $\alpha$ GlcNS concentration

$37^{\circ} \mathrm{C}$ to $47^{\circ} \mathrm{C}$ resulted in 2 - to 3 -fold increase. The addition of Pefabloc in the $47^{\circ} \mathrm{C}$ assay led to a 3-fold increase of sulphamidase activity in leukocytes, with an optimum effect obtained between 0.1 and $0.3 \mathrm{mg} / \mathrm{ml}$. At higher concentrations it was inhibitory. Using the protease inhibitor Pefabloc, heparin sulphamidase activity could be measured reliably in total leukocytes. (The method is described as the standard leukocyte assay under Materials and Methods.) Dialysis of leukocyte homogenate did not increase the sulphamidase activity appreciably. Increasing the incubation temperature from $37^{\circ} \mathrm{C}$ to $47^{\circ} \mathrm{C}$ caused a 1.5- to 2-fold increase in sulphamidase activity of lymphocytes and fibroblasts. Since the activity in fibroblasts at $37^{\circ} \mathrm{C}$ is high, this standard incubation temperature is to be preferred for diagnostic laboratories.

The heparin sulphamidase activity was determined in material from patients and controls under standard assay conditions. Sulphamidase activity in fibroblasts and lympho- 


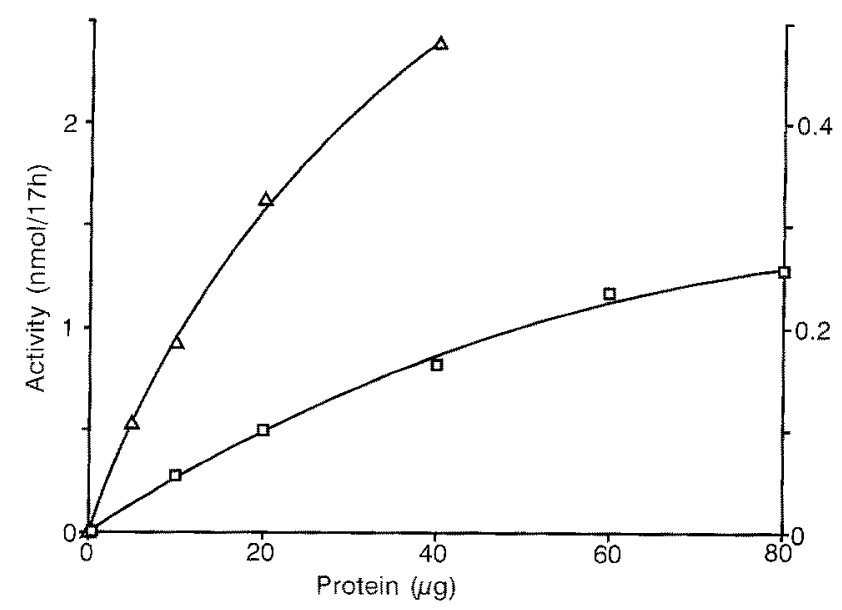

Figure 3 Protein dependence of heparin sulphamidase activity. Normal fibroblasts ( $\triangle$ : left scale) and leukocytes ( $\square$; right scale). Reaction conditions as in standard assay, except for amount of protein

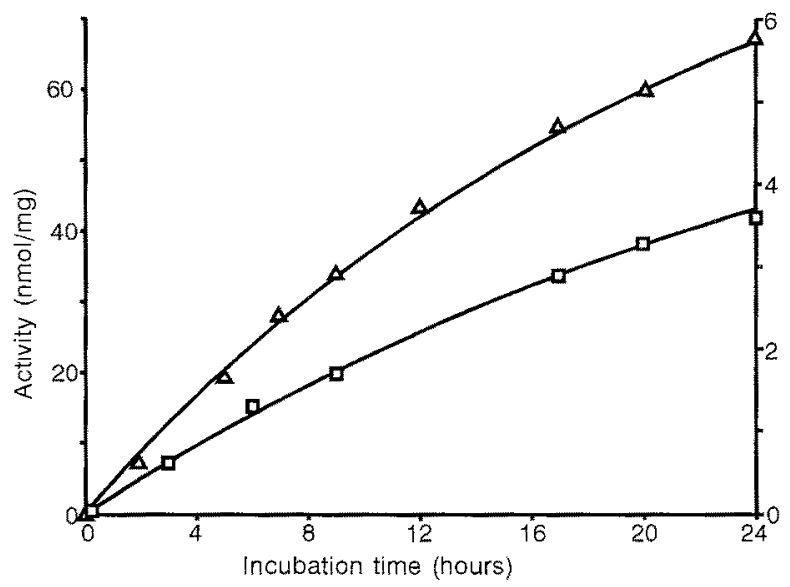

Figure 4 Time course of heparin sulphamidase activity. Normal fibroblasts ( $\triangle$; left scale) and leukocytes ( $\square$; right scale). Reaction conditions as in standard assay, except for incubation time

cytes from MPS IIIA patients was $0-3 \%$ of mean control activity (Table 1). The residual activity in total leukocytes from MPS IIIA patients was $0-10 \%$. Fibroblasts from patients with multiple sulphatase deficiency had $0.7-3.4 \%$ activity, whereas patients with Sanfilippo disease types $\mathrm{B}$ and $\mathrm{C}$ had normal sulphamidase activity. Surprisingly, all three patients with Sanfilippo D had reduced sulphamidase activity in the range for heterozygotes of MPS IIIA (Table 1).

\section{DISCUSSION}

We have defined conditions for the fluorimetric determination of heparin sulphamidase in a two-step assay, using the substrate 4-methylumbelliferyl $\alpha$-D- $N$-sulphoglucosaminide 
Table 1 Heparin sulphamidase activity in fibroblasts and leukocytes

\begin{tabular}{lccc}
\hline & \multicolumn{2}{c}{ Heparin sulphamidase activity (nmol/17h per mg protein) } \\
\cline { 2 - 4 } & Fibroblasts & Leukocytes & Lymphocytes \\
\hline Normal range & $42-152(n=28)$ & $1.8-6.8(n=11)$ & $11-20(n=7)$ \\
(mean \pm SD) & $(68 \pm 24)$ & $(4.1 \pm 1.4)$ & $(13.7 \pm 3.3)$ \\
MPS IIIA patients, range & $0.0-2.2(n=42)$ & $0.0-0.4(n=8)$ & $0.3(n=1)$ \\
MPS IIIA carriers, range & $15-43(n=10)$ & & \\
(mean \pm SD) & $(31 \pm 7)$ & & \\
Multiple sulphatase deficiency & $0.5 ; 2.3(n=2)$ & & \\
MPS IIB & $66(n=1)$ & & \\
MPS IIIC & $73(n=1)$ & \\
MPS IIID & $26 ; 32 ; 38(n=3)$ & \\
\hline
\end{tabular}

Table 2 Inhibitors of heparin sulphamidase activity

\begin{tabular}{lc}
\hline & $\begin{array}{c}\text { Relative } \\
\text { sulphamidase activity (\%) }\end{array}$ \\
\hline Various buffers at pH $\mathbf{5 . 8}$ & 100 \\
Sodium acetate & 100 \\
Michaelis' barbital/sodium acetate & $<5$ \\
Gomori's Tris/maleate & 10 \\
Sodium citrate $/ \mathrm{NaOH}$ & 10 \\
Sodium citrate/citric acid & 50 \\
Imidazole/HCl & \\
Anions in barbital/sodium acetate & 1.5 \\
Sulphate $(0.1 \mathrm{~mol} / \mathrm{L})$ & 2 \\
Phosphate $(0.1 \mathrm{~mol} / \mathrm{L})$ & \\
\hline
\end{tabular}

(MU- $\alpha$ GlcNS). Desulphation is accomplished by heparin sulphamidase and the fluorochrome $\mathrm{MU}$ is released from the reaction intermediate $\left(\mathrm{MU}-\alpha \mathrm{GlcNH}{ }_{2}\right)$ during a second incubation with $\alpha$-glucosidase, which also has $\alpha$-glucosaminidase activity (Wang He et al, unpublished observation).

MU- $\alpha$ GIcNS was shown to be useful in the diagnosis of Sanfilippo type A disease. The residual heparin sulphamidase activity in fibroblasts, leukocytes or lymphocytes from the 48 MPS IIIA patients investigated was $0-3 \%$ of the mean control activity. ${ }^{35} \mathrm{~S}$-Radiolabelled heparin is by far the most widely used substrate for assay of heparin sulphamidase. This method, originally described by Kresse et al (1973), is inconvenient because the substrate has a short half-life and it needs to be repurified regularly. Furthermore, separation techniques are required to isolate the reaction product; the relationship between amount of protein and enzyme activity is poor; and reproducibility of the assay occasionally causes problems, e.g. high residual activity in MPS IIIA patients. Our fluorogenic assay is sensitive (Table 1), requiring only $10 \mu \mathrm{g}$ protein from a fibroblast homogenate, and specific with low residual activity in patients $(<3 \%)$. It is obviously more convenient than the conventional assay. The assay, which was adequate for fibroblast and lymphocytes, was 
too insensitive for total leukocytes. Since leukocytes are the most widely used material for enzyme analysis, we have modified the assay to increase the activity in control leukocytes. These modifications, raising the incubation temperature to $47^{\circ} \mathrm{C}$, increasing the substrate concentration, and adding the protease inhibitor Pefabloc (Boehringer, unpublished composition), allowed determination of heparin sulphamidase deficiency in MPS IIIA patients. Occasionally the residual activity was rather high (10\%, Table 1).

Carrier detection in fibroblasts with this assay was informative in 9 out of 10 of the obligate heterozygotes having reduced sulphamidase activity.

The natural substrate for heparin sulphamidase is polymeric heparin or heparan sulphate; thus heparin sulphamidase is always exposed to the terminal oligomeric stretch of heparin. Hopwood and co-workers (Hopwood and Elliott 1981a,b; Freeman and Hopwood 1986) have prepared a series of di-, tri- and tetrasaccharides derived from heparin, and investigated the importance of the saccharides adjacent to the terminal $N$-sulphated glucosamine. Using a series of structurally different disaccharides, it was shown that the presence of a $C-6$ carboxyl group and a $\mathrm{C}-2 \quad O$-sulphate on the adjacent uronic acid moiety increased sulphamidase activity $100-800$ times. Increasing the substrate length by two residues led to a 10 -fold increased sulphamidase activity, relative to the best disaccharide substrate (Hopwood and Elliott 1982); free GlcNS was not de- $N$-sulphated under these conditions (Hopwood and Elliott 1981b). These results implied an essential role for the structure of the adjacent residues in the mechanism of action or binding of sulphamidase towards oligosaccharides with terminal $N$-sulphated glucosamine. The $V_{\max }$ for MU- $\alpha$ GlcNS is essentially the same as the $V_{\max }$ for the best oligosaccharide, a tetrasaccharide (Hopwood and Elliott 1982). This demonstrates that heparin sulphamidase has no absolute requirement for adjacent heparin-specific saccharides for its enzymatic action. Our results suggest that the presence of any group linked $\alpha$-glycosidically to $N$-sulphoglucosamine is sufficient to create a substrate for heparin sulphamidase. However, the $K_{m}$ of our derivatized monosaccharide substrate ( $4 \mathrm{mmol} / \mathrm{L}$ ) is much greater than those for the oligosaccharides: GlcNSIdOA, 35-220 $\mu \mathrm{mol} / \mathrm{L}$ (Hopwood and Elliott 1981a,b; Freeman and Hopwood 1986); GlcNS-UA-GlcNS-UOA, $30 \mu \mathrm{mol} / \mathrm{L}$ (Hopwood and Elliott 1982): GlcNS-IdoA-GlcNSIdOA, $10 \mu \mathrm{mol} / \mathrm{L}$ (Freeman and Hopwood 1986). This suggests that the adjacent saccharides contribute to the binding of the substrates, especially at low substrate concentrations.

Assays with MU substrates requiring more than one enzyme to yield the fluorochrome are uncommon. This principle was successfully applied for the first time to a new assay of galactose-6-sulphate sulphatase for the diagnosis of Morquio disease type A (Van Diggelen et al 1990) and recently for acetyl-CoA:glucosaminide $N$-acetyltransferase, which facilitated the diagnosis of Sanfilippo disease type C (Voznyi et al 1993). This approach could also result in replacement of other cumbersome radiochemical assays. Potential MU substrates for iduronate- and glucuronate-2-sulphatase are currently being synthesized.

\section{ACKNOWLEDGEMENTS}

We thank Professor Hans Galjaard for his continuing support. This work was supported by INTAS (International Association for the Promotion of Co-operation with Scientists from the former Soviet Union; project 94-3625). We thank Drs Ries Duran and Frans Scholte for making available blood from an MPS IIIA patient for lymphocyte isolation. Doctors 
Ron Wevers and Jan Bakkeren are kindly acknowledged for making available fibroblasts from patients with Sanfilippo type D. We also thank Dr D.J, van Rhenen and the staff of the 'Bloedbank, Rotterdam' for providing indispensable blood samples from control individuals.

\section{REFERENCES}

Freeman C, Hopwood JJ (1986) Human liver sulphamate sulphohydrolase. Biochem J 234: 83-92. Hopwood JJ, Elliott H (1981a) Sulphamidase activity in leucocytes, cultured skin fibroblasts and amniotic cells: diagnosis of Sanfilippo A syndrome with the use of a radiolabelled disaccharide substrate. Clin Sci 61: 729-735.

Hopwood JJ, Elliott H (1981b) Radiolabelled oligosaccharides as substrates for the estimation of sulfamidase and the detection of Sanfilippo type A syndrome. Clin Chim Acta 112: 55-66.

Hopwood JJ, Elliott H (1982) Diagnosis of Sanfilippo type A syndrome by estimation of sulfamidase activity using a radiolabelled tetrasaccharide substrate. Clin Chim Acta 123: 241-250.

Kresse H (1973) Mucopolysaccharidosis IIIA (Sanfilippo A disease): deficiency of heparan sulphamidase in skin fibroblasts and leucocytes. Biochem Biophys Res Commun 54: 1111-1118.

Neufeld EF, Muenzer J (1995) The mucopolysaccharidoses. In Scriver CH, Beaudet AL, Sly WS, Valle D, eds. The Metabolic and Molecular Bases of Inherited Disease. New York: McGraw-Hill, 2465-2495.

Van Diggelen OP. Zhao H, Kleijer WJ, et al (1990) A fluorimetric enzyme assay for the diagnosis of Morquio disease type A (MPS IVA). Clin Chim Acta 187: 131-140.

Voznyi Ya V, Afanasyeva SV, Kalicheva IS, Galoyan AA (1991) 2-Deoxy-2-trifluoroacetamido- $\beta$ D-glucopyranosyl fluoride in the synthesis of fluorogenic $\alpha$ - and $\beta$-N-acetylglucosaminides. Bioorganicheskaya Khimia 17: $1251-1257$.

Voznyi Ya V, Karpova EA, Dudukina TV, et al (1993) A fluorimetric enzyme assay for the diagnosis of Sanfilippo disease C (MPS IIIC). J Inher Metab Dis 16: 465-472.

Whiteman P, Young E (1977) The laboratory diagnosis of Sanfilippo disease. Clin Chim Acta 76: $139-147$. 